\title{
Does training of general practitioners for intensive treatment of people with screen-detected diabetes have a spillover effect on mortality and cardiovascular morbidity in 'at risk' individuals with normoglycaemia? Results from the ADDITION-Denmark cluster-randomised controlled trial
}

\author{
Rebecca K. Simmons ${ }^{1,2,3,4}$ • Niels H. Bruun ${ }^{2}$ - Daniel R. Witte ${ }^{2,3}$ • Knut Borch-Johnsen ${ }^{5}$. \\ Marit E. Jørgensen $^{6,7}$ • Annelli Sandbæk ${ }^{2}$ - Torsten Lauritzen ${ }^{2}$
}

Received: 29 November 2016 / Accepted: 8 February 2017 /Published online: 9 March 2017

(C) The Author(s) 2017. This article is published with open access at Springerlink.com

\begin{abstract}
Aims/hypothesis Within a trial of intensive treatment of people with screen-detected diabetes, we aimed to assess a potential spillover effect of the trial intervention on incident cardiovascular disease (CVD) and all-cause mortality among people who screened positive on a diabetes risk questionnaire but who were normoglycaemic.

Methods In the Anglo-Danish-Dutch Study of Intensive Treatment In People with Screen-Detected Diabetes in Primary Care (ADDITION)-Denmark trial, 175 general practices were cluster-randomised into: (1) screening plus routine care of individuals with screen-detected diabetes (control group); or (2) screening plus training and support in intensive multifactorial treatment of individuals with screen-detected
\end{abstract}

Rebecca K. Simmons

rks34@cam.ac.uk

$\triangle$ Torsten Lauritzen

tl@ph.au.dk

1 MRC Epidemiology Unit, University of Cambridge School of Clinical Medicine, Cambridge, UK

2 Department of Public Health, Aarhus University, Building 1260, Bartholins Allé 2, DK-8000 Aarhus C, Denmark

3 Danish Diabetes Academy, Odense, Denmark

4 Aarhus Institute of Advanced Studies, Aarhus University, Aarhus, Denmark

5 Holbæk Hospital, Holbæk, Denmark

6 Steno Diabetes Center Copenhagen, Gentofte, Denmark

7 National Institute of Public Health, Southern Denmark University, Copenhagen, Denmark diabetes (intervention group). We identified all individuals who screened positive on a diabetes risk questionnaire in ADDITION-Denmark but were normoglycaemic following biochemical testing for use in this secondary analysis. After a median 8.9 years follow-up, we used data from national registers to compare rates of first CVD events and all-cause mortality in individuals in the routine care group with those in the intensive treatment group.

Results In total, 21,513 individuals screened positive for high risk of diabetes but were normoglycaemic on biochemical testing in ADDITION-Denmark practices between 2001 and $2006(10,289$ in the routine care group and 11,224 in the intensive treatment group). During 9 years of follow-up, there were 3784 first CVD events and 1748 deaths. The incidence of CVD was lower among the intensive treatment group compared with the routine care group (HR 0.92 [95\% CI 0.85, 0.99]). This association was stronger among individuals at highest CVD risk (heart SCORE $\geq 10$; HR 0.85 [95\% CI $0.75,0.96])$. There was no difference in mortality between the two treatment groups (HR 1.02 [95\% CI 0.92, 1.14]). Conclusions/interpretation Training of general practitioners to provide target-driven intensive management of blood glucose levels and other cardiovascular risk factors showed some evidence of a spillover effect on the risk of CVD over a 9 year period among individuals at high risk of diabetes. The effect was particularly pronounced among those at highest risk of CVD. There was no effect on mortality.

Trial registration: ClinicalTrials.gov NCT00237549

Keywords Cardiovascular disease $\cdot$ Diabetes $\cdot$ High risk . Intensive treatment $\cdot$ Normoglycaemic $\cdot$ Routine care $\cdot$ Screening $\cdot$ Spillover $\cdot$ Trial 


\section{Abbreviations \\ CVD Cardiovascular disease \\ RBG Random blood glucose}

\section{Introduction}

Screening for type 2 diabetes inevitably identifies more people at high risk of developing diabetes and cardiovascular disease (CVD) than those with undiagnosed prevalent disease. Little is known about these high risk individuals following their participation in a screening programme. While wellestablished guidelines for the treatment of diabetes exist, most countries do not specify how to treat individuals who screen positive following completion of a diabetes risk questionnaire but are normoglycaemic on biochemical testing.

In the Anglo-Danish-Dutch Study of Intensive Treatment In People with Screen-Detected Diabetes in Primary Care (ADDITION)-Denmark trial (ClinicalTrial.gov registration no. NCT00237549) [1], 175 general practices were clusterrandomised to routine care or to receive training and support in the implementation of an intensive treatment programme for individuals with screen-detected diabetes. This included lifestyle intervention and CVD risk factor management. The intervention was associated with a significant increase in redeemed cardioprotective medication and a non-significant $17 \%$ risk reduction in CVD events among individuals with screen-detected diabetes over 5 years of follow-up [2]. Given the favourable increase in cardioprotective medication observed in the intensive treatment practices, we wanted to investigate whether the education and guidelines we offered may have also had an impact on the management of patients with normal blood glucose levels following screening.

In order to assess a potential spillover effect of the trial intervention among practices taking part in ADDITIONDenmark, we compared rates of first CVD events and allcause mortality among people who screened positive on the diabetes risk questionnaire but who were normoglycaemic on biochemical testing in the routine care (control) and intensive treatment trial groups.

\section{Methods}

ADDITION-Denmark consists of two phases: (1) a stepwise screening programme; and (2) a cluster-randomised parallelgroup trial comparing the effects of intensive multifactorial treatment with routine care among individuals with screendetected type 2 diabetes [1, 2]. In brief, between 2001 and 2006, we performed a population-based stepwise screening programme among people aged 40-69 years without known diabetes in 175 general practices in Denmark. Eligible individuals were sent a diabetes risk score questionnaire [3] with an invitation to visit their family doctor for a diabetes test and a cardiovascular risk assessment (heart SCORE) [4] if they scored $\geq 5$ points (maximum 15 points) on the risk questionnaire. The diabetes risk score questionnaire estimates diabetes risk using age, sex, BMI, known hypertension, leisure time physical activity and family history of diabetes [3]. The heart SCORE estimates fatal CVD risk using age, sex, smoking, systolic blood pressure and total cholesterol [4]. Participants who attended a screening appointment underwent measurement of height, weight, blood pressure, random blood glucose (RBG), total cholesterol and $\mathrm{HbA}_{1 \mathrm{c}}$. Individuals with an $\mathrm{RBG} \geq 5.5 \mathrm{mmol} / \mathrm{l}$ or $\mathrm{HbA}_{1 \mathrm{c}} \geq 5.8 \%(40 \mathrm{mmol} / \mathrm{mol})$ were invited to return to the practice for further testing. The WHO 1999 criteria, based on a standard OGTT, were used to diagnose diabetes [5]. Participants diagnosed with type 2 diabetes were subsequently managed according to the treatment regimen to which their practice had been allocated: routine care (control) or intensive treatment. Ethical approval for the trial was granted by the Region Midt Ethical Committee, Denmark. As this was a registry-based study using anonymised data, participants did not give informed consent. This approach was approved by the Danish Data Protection Agency and the Danish Health and Medicine Authority.

For those diagnosed with diabetes, general practitioners and nurses received training and support in delivering intensive treatment via small group or practice-based educational meetings where treatment targets/algorithms, lifestyle advice and supporting evidence were discussed [2]. Intensive treatment practices received additional funding to support the delivery of care, which included target-driven management of hyperglycaemia and blood pressure and cholesterol levels by medical treatment and promotion of healthy lifestyles, based on the stepwise regimen used in the Steno-2 study and other trial results. In the routine care (control) group, general practitioners were advised to follow Danish national recommendations for diabetes treatment and received no further followup. In both groups, practitioners were encouraged to treat normoglycaemic individuals with a heart SCORE $\geq 5$, according to Danish guidelines [6].

In this secondary analysis, in order to assess the potential spillover effect of the intervention, we identified individuals who underwent screening as part of ADDITION-Denmark and who were normoglycaemic on biochemical testing. Normoglycaemia in our study refers to individuals with an $\mathrm{RBG}<5.5 \mathrm{mmol} / \mathrm{l}$ and $\mathrm{HbA}_{1 \mathrm{c}} \leq 6 \%(42 \mathrm{mmol} / \mathrm{mol})$ at the first visit/blood test, and people with fasting blood glucose $<5.6 \mathrm{mmol} / \mathrm{l}$ and $2 \mathrm{~h}$ blood glucose following an OGTT $<7.8 \mathrm{mmol} / \mathrm{l}$. Participants were followed for a median of 8.9 years to 31 December 2011, when national registers were searched for information on vital status and a composite of first event of cardiovascular death (ICD-10 codes I60 to I69, 
I20 to I25, and I46), non-fatal ischaemic heart disease (ICD10 codes I20 to I25, and I46) or non-fatal stroke (ICD-10 code I60 to I69).

Statistical analysis Characteristics were summarised separately in the intensive treatment and routine care (control) groups. Date of entry to the study was set as date of invitation to screening. Individuals were censored on the date of first event following invitation for screening (for the incident CVD analysis), upon death, or on the 31 December 2011 (final date of follow-up), depending on which occurred earliest. HRs comparing incident CVD events and all-cause mortality between the groups were estimated with a Cox proportional hazards regression model and we accounted for clustering at the general practitioner level. We tested the proportional hazards assumption by including a variable for treatment by time interaction in the Cox regression model $(p>0.05)$. We also examined these associations in all individuals with a heart SCORE of $\geq 0$ to $<5, \geq 5$ to $<10$, and $\geq 10$. All analyses were completed using Stata Version 14.1 (StataCorp, College Station, TX, USA).

Table 1 Characteristics of normoglycaemic individuals following diabetes screening in the ADDITION-Denmark study $(n=21,513)$, by treatment group

\begin{tabular}{|c|c|c|c|c|c|c|c|c|}
\hline & \multicolumn{2}{|l|}{ NGT } & \multicolumn{2}{|c|}{$\begin{array}{l}\text { NGT and heart } \\
\text { SCORE } \geq 0 \text { to }<5\end{array}$} & \multicolumn{2}{|c|}{$\begin{array}{l}\text { NGT and heart } \\
\text { SCORE } \geq 5 \text { to }<10\end{array}$} & \multicolumn{2}{|c|}{$\begin{array}{l}\text { NGT and heart } \\
\text { SCORE } \geq 10\end{array}$} \\
\hline & $\begin{array}{l}\text { Routine care } \\
\text { group } \\
(n=10,289)\end{array}$ & $\begin{array}{l}\text { Intensive } \\
\text { treatment group } \\
(n=11,224)\end{array}$ & $\begin{array}{l}\text { Routine } \\
\text { care group } \\
(n=4890)\end{array}$ & $\begin{array}{l}\text { Intensive } \\
\text { treatment group } \\
(n=5347)\end{array}$ & $\begin{array}{l}\text { Routine } \\
\text { care group } \\
(n=2450)\end{array}$ & $\begin{array}{l}\text { Intensive } \\
\text { treatment group } \\
(n=2603)\end{array}$ & $\begin{array}{l}\text { Routine care } \\
\text { group } \\
(n=1795)\end{array}$ & $\begin{array}{l}\text { Intensive } \\
\text { treatment group } \\
(n=1925)\end{array}$ \\
\hline Male sex, $n(\%)$ & $5251(51.0)$ & $5749(51.2)$ & $1627(33.3)$ & $1745(32.6)$ & $1608(65.6)$ & $1705(65.5)$ & $1515(84.4)$ & $1625(84.4)$ \\
\hline Age (SD) & $59.1(6.9)$ & $59.1(7.0)$ & $55.8(6.4)$ & $55.8(6.4)$ & $62.1(5.1)$ & $62.2(4.8)$ & $65.1(4.0)$ & $65.2(4.1)$ \\
\hline \multicolumn{9}{|l|}{ Education level, $n(\%)$} \\
\hline $0-10$ years & $3191(31.5)$ & $3608(32.6)$ & $1453(30.1)$ & $1613(30.5)$ & 835 (34.6) & $872(34.0)$ & $611(34.7)$ & $672(35.5)$ \\
\hline $10-15$ years & $4297(42.4)$ & $4555(41.1)$ & $2075(43.0)$ & $2189(41.4)$ & 1005 (41.6) & $1028(40.0)$ & $735(41.8)$ & $796(42.1)$ \\
\hline$\geq 15$ years & $2640(26.1)$ & $2908(26.3)$ & $1297(26.9)$ & $1486(28.1)$ & $575(23.8)$ & $668(26.0)$ & $414(23.5)$ & $424(22.4)$ \\
\hline Previous CVD, $n(\%)$ & $470(4.6)$ & $495(4.4)$ & $166(3.4)$ & $167(3.1)$ & $141(5.8)$ & $146(5.6)$ & $97(5.4)$ & $100(5.2)$ \\
\hline \multicolumn{9}{|c|}{$\begin{array}{l}\text { Redeemed anti-hypertensive medication, } \\
n(\%)^{\mathrm{a}}\end{array}$} \\
\hline Year 2000 & $2429(23.6)$ & $2663(23.7)$ & $1126(23.0)$ & $1199(22.4)$ & $608(24.8)$ & $667(25.6)$ & $457(25.5)$ & $506(26.3)$ \\
\hline Year 2005 & $4124(40.7)$ & 4383 (39.6) & $1749(36.1)$ & $1814(34.2)$ & $1041(43.2)$ & $1100(42.9)$ & $904(52.0)$ & 977 (52.8) \\
\hline Year 2010 & $5265(54.3)$ & $5692(53.9)$ & $2256(47.6)$ & $2411(46.8)$ & $1317(58.0)$ & $1406(57.6)$ & $1120(70.8)$ & 1198 (71.4) \\
\hline \multicolumn{9}{|c|}{$\begin{array}{l}\text { Redeemed glucose-lowering medication, } \\
n(\%)^{\mathrm{a}}\end{array}$} \\
\hline \multicolumn{9}{|l|}{ Year $2000^{\mathrm{b}}$} \\
\hline Year 2005 & $21(0.2)$ & $21(0.2)$ & $9(0.2)$ & $12(0.2)$ & $5(0.2)$ & $\mathrm{b}$ & $6(0.3)$ & $5(0.3)$ \\
\hline Year 2010 & $156(1.6)$ & $184(1.7)$ & $74(1.6)$ & $86(1.7)$ & $34(1.5)$ & $43(1.8)$ & $39(2.5)$ & $33(2.0)$ \\
\hline \multicolumn{9}{|c|}{$\begin{array}{l}\text { Redeemed lipid-lowering medication, } \\
n(\%)^{\mathrm{a}}\end{array}$} \\
\hline Year 2000 & $383(3.7)$ & $374(3.3)$ & $138(2.8)$ & $135(2.5)$ & $125(5.1)$ & $112(4.3)$ & $86(4.8)$ & $100(5.2)$ \\
\hline Year 2005 & $1573(15.5)$ & $1692(15.3)$ & $602(12.4)$ & $638(12.0)$ & $452(18.7)$ & $487(19.0)$ & $369(21.2)$ & $401(21.7)$ \\
\hline Year 2010 & $3035(31.3)$ & $3238(30.7)$ & $1247(26.3)$ & $1341(26.0)$ & $779(34.3)$ & $845(34.6)$ & $652(41.2)$ & $685(40.8)$ \\
\hline HR for CVD $(95 \% \mathrm{CI})$ & \multicolumn{2}{|c|}{$0.92(0.85,0.99)$} & \multicolumn{2}{|c|}{$0.90(0.80,1.02)$} & \multicolumn{2}{|c|}{$0.98(0.84,1.13)$} & \multicolumn{2}{|c|}{$0.85(0.75,0.96)$} \\
\hline $\begin{array}{l}\text { HR for all-cause } \\
\text { mortality }(95 \% \mathrm{CI})\end{array}$ & \multicolumn{2}{|c|}{$1.02(0.92,1.14)$} & \multicolumn{2}{|c|}{$1.07(0.89,1.30)$} & \multicolumn{2}{|c|}{$0.88(0.75,1.04)$} & \multicolumn{2}{|c|}{$1.06(0.90,1.26)$} \\
\hline
\end{tabular}

Data are presented as $n(\%)$, mean (SD) or HR (95\% CI)

Please note that numbers in the three heart SCORE groups do not add up to the total cohort size $(n=21,513)$ because of missing data for some individuals, which prevented us from computing the heart SCORE. Similarly, numbers for education do not add up to the total cohort size because of missing data

${ }^{a}$ Numbers for cardioprotective medication in years 2005 and 2010 were calculated using the individuals who were alive at the beginning of that year as the denominator

${ }^{\mathrm{b}}$ Numbers for redeemed glucose-lowering medication are too small to report (Statistics Denmark regulations)

NGT, normal glucose tolerance 

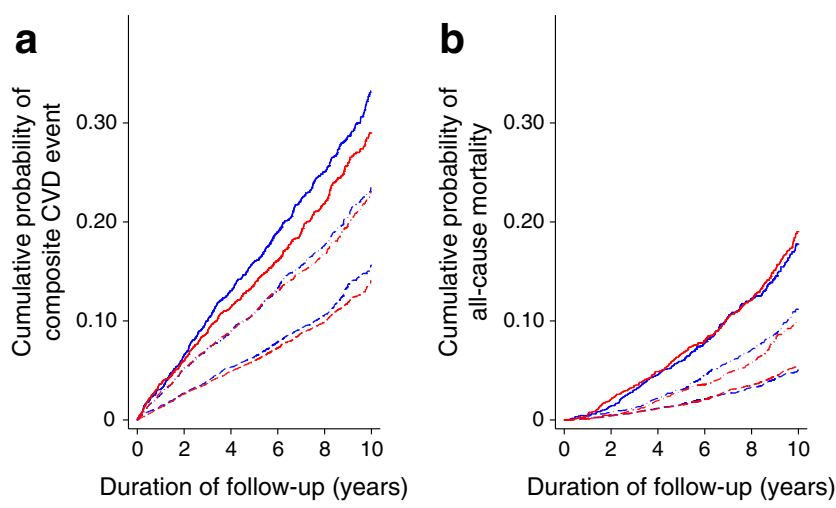

Fig. 1 Cumulative incidence of (a) CVD and (b) all-cause mortality among individuals with normal glucose tolerance in the ADDITIONDenmark intensive treatment and routine care groups (2001-2011). This figure is unadjusted. Routine care group, blue; intensive treatment group, red. Heart SCORE $\geq 0$ to $<5$, dashed line; heart SCORE $\geq 5$ to $<10$, dot/dash line; heart SCORE $\geq 10$, solid line

\section{Results}

Between 2001 and 2006, 21,513 individuals were found with normal blood glucose following screening in ADDITIONDenmark practices $(10,289$ in the routine care [control] group and 11,224 in the intensive treatment group). The groups had similar baseline characteristics, with similar proportions of men $(51 \%)$ and numbers of individuals with $>15$ years education $(26 \%)$ and previous CVD $(\sim 4.5 \%$; Table 1$)$. The mean age in both groups was 59 years. The proportion of individuals redeeming lipid-lowering, glucose-lowering and antihypertensive medication was similar throughout follow-up (Table 1).

Median (interquartile range) duration of follow-up was 8.9 years (8.2-10.0). During follow-up, there were 1904 CVD events $(17.0 \%)$ in the intensive treatment group and $1880(18.3 \%)$ events in the routine care group. The incidence of CVD was lower among the intensive treatment group compared with the routine care group (HR 0.92 [95\% CI 0.85 , 0.99]; Table 1 and Fig. 1a). This association was more pronounced among individuals with a heart SCORE $\geq 10$ (HR 0.85 [95\% CI $0.75,0.96])$. There were 923 deaths $(8.2 \%)$ in the intensive treatment group and $825(8.0 \%)$ deaths in the routine care group. Of these, $125(13.5 \%)$ and 106 (12.8\%) were CVD-related deaths in the intensive treatment and routine care groups, respectively. The incidence of all-cause mortality was similar between the two treatment groups (HR 1.02 [95\% CI 0.92, 1.14]; Table 1 and Fig. 1b) across all levels of CVD risk.

\section{Discussion}

We found some evidence for a spillover effect from the intensive treatment of people with screen-detected diabetes to those with normal blood glucose levels. Among normoglycaemic individuals, the incidence of CVD was significantly lower in the intensive treatment compared with the routine care (control) group. There was no difference in the mortality experience of the two groups.

We previously showed that the training of general practitioners in intensive treatment of diabetes in the ADDITIONDenmark study had no spillover effect on progression to diabetes in individuals with impaired fasting glucose or impaired glucose tolerance [7]. There are very few other studies examining the spillover effect of a trial intervention in general practice with which to compare our results. In general, interventions targeting healthcare professionals seem to be beneficial only if baseline $\mathrm{HbA}_{1 \mathrm{c}}$ control is poor [8, 9]. Our finding of reduced rates of CVD among individuals with normoglycaemia may therefore be considered somewhat surprising. However, as individuals who have a positive diabetes risk score are at high risk of CVD and mortality whether or not subsequent testing shows them to have diabetes [10], this is a welcome observation. While we did not find a difference in the rates of redeemed medication between groups, we hypothesise that training and support of general practitioners in the intensive treatment arm of the trial may have improved the management of lifestyle behaviour, and maybe medication adherence, among patients identified at high risk but without diabetes on biochemical testing. One-third of screen-detected individuals with diabetes in ADDITION-Denmark reported that they had stopped smoking at the 5 year follow-up. Furthermore, this whole cohort lost an average of $2 \mathrm{~kg}$ in weight [2]. Similar behavioural responses among individuals identified at high CVD risk may provide a potential mechanism for the observed CVD risk reduction alongside prescribed treatment.

Overall, there was evidence of suboptimal routine treatment among individuals who screened positive for high risk of diabetes but were normoglycaemic upon biochemical testing in ADDITION-Denmark. Under routine care, general practitioners were advised to treat individuals at high CVD risk e.g. with a heart SCORE $\geq 5$. However, even among people with a heart SCORE $\geq 10$, the medication data show that less than $22 \%$ of individuals were on lipid-lowering treatment in 2005 and less than $42 \%$ in 2010 . All participants in this group should have been prescribed lipid-lowering drugs according to national guidelines [5]. As well as evidence of 'undertreatment', there also appeared to be a considerable delay in starting treatment among this high-risk population.

While our intervention was associated with a small absolute risk reduction for individuals with normoglycaemia in the entire cohort, there was a clinically meaningful risk reduction among individuals at highest CVD risk (heart SCORE $\geq 10$ ). We suggest that the reduction in cardiovascular events might have been greater if general practitioners were convinced to treat according to guidelines for cardiovascular risk management. 
In the current study, the Danish registry system allowed us to investigate the long-term experience of individuals found to have normal glucose tolerance following screening in ADDITION-Denmark practices between 2001 and 2011. Trial groups were well balanced for patient level characteristics at baseline. Outcome ascertainment was very robust. The Danish National Death Registry estimates $100 \%$ coverage of mortality based on death certificates, while the National Patient Registry includes 99.4\% of discharges from Danish hospitals. The vast majority of participants were white European, the main ethnic group in Denmark, which limits generalisability to other settings. It would have been interesting to examine trends in lifestyle factors, such as smoking, diet and physical activity, which might have accounted for some of the difference in CVD rates we observed, but data were not available for this cohort.

In conclusion, training of general practitioners to provide target-driven intensive management of blood glucose levels and other cardiovascular risk factors showed some evidence of a spillover effect on the risk of CVD among the normoglycaemic population. The effect was particularly pronounced among those at highest risk of CVD.

Acknowledgements We gratefully acknowledge the contribution of all participants, practice nurses and general practitioners in the ADDITIONDenmark study. With special thanks to M. Pedersen (Department of Public Health, University of Aarhus, Aarhus, Denmark) for her help with retrieving data from Statistics Denmark.

Data availability The data used in this paper was a combination of data obtained from the ADDITION study and data from national Danish Registers at Denmark Statistics (DST). The ADDITION study data were obtained after a written application to the data owner, A. Sandbæk (Institute of Public Health, Aarhus University, Aarhus, Denmark; annelli.sandbaek@ph.au.dk). Data from DST were made available following an application to DST (www.dst.dk/en/TilSalg/ Forskningsservice). Data from ADDITION and DST were merged by DST and analyses were performed via a secure Virtual Private Network (VPN) connection. In accordance with the Danish Act of processing of personal data, future interested researchers must perform the steps mentioned above to obtain access to the data.

Funding ADDITION-Denmark was supported by the national health services in the counties of Copenhagen, Aarhus, Ringkøbing, Ribe and South Jutland in Denmark, the Danish Council for Strategic Research, the Danish Research Foundation for General Practice, Novo Nordisk Foundation, the Danish Centre for Evaluation and Health Technology Assessment, the diabetes fund of the National Board of Health, the Danish Medical Research Council and the Aarhus University Research Foundation. The trial has been supported by unrestricted grants from Novo Nordisk A/S, Novo Nordisk Scandinavia AB, Novo Nordisk UK, ASTRA Denmark, Pfizer Denmark, GlaxoSmithKline Pharma Denmark, Servier Denmark AS and HemoCue Denmark AS. The study sponsor was not involved in the design of the study; the collection, analysis and interpretation of data; writing the report; or the decision to submit the report for publication.
Duality of interest DRW and RKS are supported by the Danish Diabetes Academy, which is funded by the Novo Nordisk Foundation. RKS is further supported by the Aarhus Institute of Advanced Studies. DRW reports receiving lecture fees from Novo Nordisk A/S and Steno Diabetes Center. DRW, MEJ and TL hold shares in Novo Nordisk A/S. TL reports receiving a travel reimbursement for attending meetings on early detection and treatment of diabetes in 2015 and 2016. These meetings were held by the International Diabetes Federation (IDF) and Primary Care Diabetes Europe, and were sponsored by Astra Zeneca. AS reports receiving lecture fees for providing continuing medical education to general practitioners. MEJ is the principal investigator of an investigator initiated trial sponsored by Astra Zeneca and reports receiving lecture fees from Astra Zeneca. All other authors declare that there is no duality of interest associated with their contribution to this manuscript.

Contribution statement NHB and TL had full access to all of the data in the study and take responsibility for the accuracy of the data analysis. TL acts as guarantor for this paper. AS, TL and KB-J designed the ADDITION-Denmark study and are principal investigators for the trial. DRW, MEJ, AS and TL developed the study proposal. NHB, DRW and TL participated in the acquisition of the data from Statistics Denmark. NHB analysed the data. RKS drafted the report. DRW, RKS, KB-J, MEJ, AS and TL participated in the interpretation of the data and critical revision of the report for important intellectual content. All co-authors gave final permission for this version of the manuscript to be published.

Open Access This article is distributed under the terms of the Creative Commons Attribution 4.0 International License (http:// creativecommons.org/licenses/by/4.0/), which permits unrestricted use, distribution, and reproduction in any medium, provided you give appropriate credit to the original author(s) and the source, provide a link to the Creative Commons license, and indicate if changes were made.

\section{References}

1. Lauritzen T, Griffin S, Borch-Johnsen K, Wareham NJ, Wolffenbuttel BH, Rutten G (2000) The ADDITION study: proposed trial of the cost-effectiveness of an intensive multifactorial intervention on morbidity and mortality among people with Type 2 diabetes detected by screening. Int J Obes Relat Metab Disord 24(Suppl 3):S6-S11

2. Griffin SJ, Borch-Johnsen K, Davies MJ et al (2011) Effect of early intensive multifactorial therapy on 5-year cardiovascular outcomes in individuals with type 2 diabetes detected by screening (ADDITION-Europe): a cluster-randomised trial. Lancet 378: 156-167

3. Glumer C, Carstensen B, Sandbaek A, Lauritzen T, Jorgensen T, Borch-Johnsen K (2004) A Danish diabetes risk score for targeted screening: the Inter99 study. Diabetes Care 27:727-733

4. Perk J, De Backer G, Gohlke H et al (2012) European Guidelines on cardiovascular disease prevention in clinical practice. The Fifth Joint Task Force of the European Society of Cardiology and Other Societies on Cardiovascular Disease Prevention in Clinical Practice (constituted by representatives of nine societies and by invited experts). Eur Heart J 33:1635-1701

5. WHO (1999) definition, diagnosis, and classification of diabetes mellitus and its complications: report of a WHO consultation. In: WHO (ed) Geneva. Available from http://apps.who. int/iris/bitstream/10665/66040/1/WHO_NCD_NCS_99.2.pdf, accessed 13 February 2017

6. Dansk Selskab for Almen Medicin(1998)Forebyggelse afhjertesygdomi almen praksis - med særligt henblik på dyslipidæmi (Prevention of heart 
disease in general practice - with particular focus on dyslipidaemia). Updated 2002 and 2007. In: Dansk Selskab for Almen Medicin (ed) Odder. Available from http://www.dsam.dk/files/9/iskaemisk_hjerte_ kar_sygdom_2007.pdf, accessed 13 February 2017

7. Rasmussen SS, Glumer C, Sandbaek A, Lauritzen T, BorchJohnsen K (2008) General effect on high-risk persons when general practitioners are trained in intensive treatment of type 2 diabetes. Scand J Prim Health Care 26:166-173

8. Lauritzen T, Sandbaek A, Carlsen AH, Borch-Johnsen K (2012) All-cause mortality and pharmacological treatment intensity following a high risk screening program for diabetes. A 6.6 year follow-up of the ADDITION study, Denmark. Prim Care Diabetes 6:193-200

9. Tricco AC, Ivers NM, Grimshaw JM et al (2012) Effectiveness of quality improvement strategies on the management of diabetes: a systematic review and meta-analysis. Lancet 379:2252-2261

10. Spijkerman A, Griffin S, Dekker J, Nijpels G, Wareham NJ (2002) What is the risk of mortality for people who are screen positive in a diabetes screening programme but who do not have diabetes on biochemical testing? Diabetes screening programmes from a public health perspective. J Med Screen 9:187-190 